\section{Case Reports in Ophthalmology}

Case Rep Ophthalmol 2016;7:193-197

DOI: 10.1159/000450675 Publisned online: October 11, 2016
(C) 2016 The Author(s)

Published by S. Karger AG, Basel www.karger.com/cop

This article is licensed under the Creative Commons Attribution-NonCommercial 4.0 International License (CC BY-NC) (http://www.karger.com/Services/OpenAccessLicense). Usage and distribution for commercial purposes requires written permission.

\title{
Successful Restoration of Visual Acuity with an Extended Range of Vision Intraocular Lens after Multifocal Laser Ablation
}

\author{
Sondra Black \\ Crystal Clear Vision, Toronto, Ont., Canada
}

\section{Keywords}

Extended range of vision · TECNIS Symfony $\cdot$ LASIK $\cdot$ Multifocal laser ablation $\cdot$ Visual outcome

\begin{abstract}
As our baby boomer population is aging and developing cataracts, so are our post-LASIK patients. These patients underwent LASIK surgery as they wished to be spectacle-free and are hoping to remain so after intraocular lens (IOL) surgery. Unfortunately, very little information is available regarding the suitability of presbyopia correcting IOLs for post-LASIK patients. This case represents successful implantation of an extended range of vision IOL in a 59-yearold patient who underwent multifocal ablation excimer laser surgery 12 years before. Emmetropia was targeted for the dominant eye and $-0.5 \mathrm{D}$ for the fellow eye. The 13 month followup after bilateral implantation of the TECNIS Symfony IOL revealed an uncorrected visual acuity of 20/25 for distance, 20/20 for intermediate and 20/16 for near. The patient is very happy and did not report any visual symptoms when asked. This successful case should encourage surgeons to consider implanting an extended range of vision IOLs in post-LASIK patients.




\section{Case Reports in Ophthalmology}

\section{Introduction}

Millions of patients underwent LASIK in their 20s and 30s when this technology emerged in the early 1990s. They are now reaching the age at which presbyopia and/or cataracts develop. These patients have already expressed their wish to be spectacle independent and made the decision to undergo refractive surgery. It seems to be logical to assume that these patients would continue to be interested in remaining spectacle-free, and therefore the probability is high that they would opt for a presbyopia-correcting intraocular lens (PCIOL) if given the option. Unfortunately, there are limited data available regarding successful visual restoration with PCIOL implantation in patients having undergone previous refractive laser surgery [1]. The few available published studies have been mainly performed by the same research group with the same lens models [2-5]. To our best knowledge, nothing has been published on the use of accommodating, enhanced depth of focus and extended range of vision (ERV) intraocular lenses (IOLs). We present a case with successful implantation of the ERV IOL TECNIS Symfony (Abbott Medical Optics, Santa Ana, Calif., USA) in a patient with previous multifocal ablation excimer laser surgery.

\section{Case Report}

A 46-year-old myopic male patient underwent multifocal ablation refractive laser surgery (LVC) in 2003 when he was 46 years old. The treatment was performed with the patented VISX (Abbott Medical Optics) multifocal ablation pattern that was created using the Wavescan aberrometer during a feasibility study. This system was customized to ablate a central, steepened zone for near correction and a peripheral zone targeted for distance. The central steepening after the multifocal ablation can be seen in figure 1. He presented at our clinic in late 2014 and was interested in a presbyopia-correcting solution as his reading vision had dropped recently. His optical scatter index was elevated to 2.8 (OD) and 2.3 (OS) indicating changes in lens nuclear density. His refraction was slightly hyperopic at that time.

We suggested a bilateral implantation of an ERV IOL, the TECNIS Symfony. The patient was informed in detail about the challenges of IOL calculation after LVC and the potential limitations of PCIOLs and agreed to undergo surgery in May 2015. His preoperative refraction was $+0.50 /-0.50 \times 165$ in the right eye and $+0.50 /-0.50 \times 005$ in the left eye. For the IOL calculation we targeted emmetropia in his dominant left eye and $-0.50 \mathrm{D}$ in his right eye. The Haigis L formula was used for lens calculations.

One day postoperatively the patient's refraction was -1.00 (OD) and $-0.75 /-0.25 \times 165$ (OS) but binocularly his distance visual acuity was $20 / 25$. With distance correction in place, his visual acuity was still 20/20 at near, intermediate and distance.

After 1 week, his uncorrected binocular visual acuity was 20/25 at distance, 20/30 at intermediate and $20 / 20$ at near. Both eyes had a monocular corrected visual acuity of $20 / 20$ at distance. His refraction was $-0.25 \mathrm{D} /-1.25 \mathrm{D} \times 110^{\circ}(\mathrm{OD})$ and $-0.50 \mathrm{D} /-0.50 \mathrm{D} \times 180$ (OS). Although the patient was slightly myopic in both eyes, he was very satisfied with the quality of his vision.

Thirteen months after surgery, the patient's binocular visual acuity was 20/25 at distance, 20/20 at intermediate and 20/16 at near. When his mild myopia was corrected to plano in both eyes, his visual acuity increased to 20/20 at distance, 20/20 at intermediate and still 20/20 at near. The patient is very satisfied with the outcome and not bothered by any night vision issues or other photic phenomena. 


\section{Case Reports in Ophthalmology}

\section{Discussion}

This case represents successful implantation of an ERV IOL 12 years after multifocal ablation in a patient with the strong desire for spectacle independence. His uncorrected visual acuity across all distances was excellent at the last follow-up, which was 13 months after surgery. The patient did not experience any visual symptoms and is very happy.

Multifocal ablations for treatment of presbyopia with the excimer laser can be performed either by steepening the peripheral cornea for near vision and using the central cornea for distance vision [6-8] or by customized ablation patterns for a central, steepened zone for near correction and a peripheral zone targeted for distance [9-11]. Our patient had a steepened central zone for enhanced near vision. To our best knowledge, no publications exist on PCIOL implantation after multifocal laser ablation.

A few studies investigated the outcome of multifocal IOL (MIOL) implantation after myopic and hyperopic LASIK. Alfonso et al. [2] compared visual acuity under photopic and mesopic conditions with and without glare, as well as higher-order aberrations (HOAs) between patients after myopic LASIK who were implanted either with the diffractive Acri.LISA 366D IOL (Acri.Tec GmbH, Germany) or with the apodized refractive-diffractive Acrysof ReSTOR SN60D3 IOL (Alcon Laboratories, Fort Worth, Tex., USA). A third group with phakic eyes after myopic LASIK served as a control. Mean photopic corrected visual acuity (CDVA) after 6 months was 20/25 or better in all groups. Under glare or low-contrast situations, the Acri.LISA patients performed better than the ReSTOR patients. All eyes in both IOL groups achieved a distance-corrected near visual acuity (DCNVA) of 20/32 or better. There were no differences in HOAs between groups. The same authors evaluated further parameters in a second publication on the same patient cohort and concluded that the optical and visual performance of the Acri.LISA eyes was comparable to eyes in the control group, but that the group with this lens performed better than the ReSTOR group [3].

The same research group investigated the outcome after implantation of a spherical diffractive IOL (Acrysof ReSTOR SN60D3) in eyes with previous hyperopic LASIK [4]. After 6 months, mean CDVA was $20 / 25$ or better in $58.54 \%$ of the patients. Mean UDVA and CDVA were 20/26 and 20/22, and the patients achieved a mean UNVA and DCNVA of 20/21, respectively. In a second evaluation of further parameters, the authors reported a comparable visual performance of the ReSTOR eyes and a control group with phakic eyes after hyperopic LASIK under photopic conditions, but a worse outcome of the IOL group under mesopic conditions [5].

The results after myopic and hyperopic LASIK suggest that the implantation of diffractive multifocal lenses is a viable option for presbyopia correction. However, the patients should be informed about the potential risk of a refractive surprise and the possibility of poorer visual performance under low light conditions, beyond what they may have already experienced after LASIK.

Our case is only partly comparable to the outcomes of the discussed studies because our patient had a multifocal ablation before IOL implementation, and the implanted IOL has a different optical principle. This ERV optical technology of the TECNIS Symfony IOL provides a full range of vision with reduced incidence of halos and glare and contrast sensitivity close to that typically associated with monofocal IOLs [12]. The basis of this technology is an achromatic diffractive echelette design that corrects the corneal chromatic aberration for enhanced contrast sensitivity and generates an ERV [12]. Correcting chromatic aberration in combination with the correction of spherical aberration has been shown to improve retinal image quality with no impact on the depth of focus [13]. Chromatic aberration causes blur 


\section{Case Reports in Ophthalmology}

Black: Successful Restoration of Visual Acuity with an Extended Range of Vision Intraocular Lens after Multifocal Laser Ablation

and reduction in contrast vision [14]. Therefore, the correction of corneal chromatic aberration with an IOL should result in an improved focus of light. It would be interesting to study the interaction of a multifocal ablation profile with the asphericity of an IOL. In our case, the patient did not report any adverse visual symptoms which would indicate such interaction.

Clinical data with the TECNIS Symfony IOL do not show the typical behavior of MIOLs as this lens has an elongated focal area instead of multiple focal points [15]. In addition to the improved intermediate vision, an important advantage is the low occurrence of photic phenomena and visual symptoms [15], which are typically seen with MIOLs as one image is in focus while the out-of-focus image is suppressed. Visual symptoms, such as halos, are caused by this out-of-focus image.

In conclusion, our case demonstrates that excellent distance, intermediate and near visual acuity results can be achieved with an ERV IOL after multifocal excimer laser ablation. We would like to encourage surgeons to feel comfortable utilizing this type of IOL in the increasing number of post-LASIK patients who seek spectacle independence. Controlled studies are needed to create evidence for the suitability of PCIOLs in patients with a history of myopic, hyperopic and multifocal excimer laser ablation.

\section{Statement of Ethics}

The authors have no ethical conflicts to disclose.

\section{Disclosure Statement}

Dr. Black reports grants from Visx during the conduct of the study.

\section{References}

1 Khor WB, Afshari NA: The role of presbyopia-correcting intraocular lenses after laser in situ keratomileusis. Curr Opin Ophthalmol 2013;24:35-40.

2 Alfonso JF, Madrid-Costa D, Poo-Lopez A, Montes-Mico R: Visual quality after diffractive intraocular lens implantation in eyes with previous myopic laser in situ keratomileusis. J Cataract Refract Surg 2008;34:1848-1854.

-3 Fernandez-Vega L, Madrid-Costa D, Alfonso JF, et al: Optical and visual performance of diffractive intraocular lens implantation after myopic laser in situ keratomileusis. J Cataract Refract Surg 2009;35:825-832.

4 Alfonso JF, Fernandez-Vega L, Baamonde B, et al: Refractive lens exchange with spherical diffractive intraocular lens implantation after hyperopic laser in situ keratomileusis. J Cataract Refract Surg 2009;35:1744-1750.

5 Alfonso JF, Fernandez-Vega L, Baamonde B, et al: Visual quality after diffractive intraocular lens implantation in eyes with previous hyperopic laser in situ keratomileusis. J Cataract Refract Surg 2011;37:1090-1096.

-6 Alió JL, Chaubard JJ, Caliz A, Sala E, Patel S: Correction of presbyopia by technovision central multifocal LASIK (presbyLASIK). J Refract Surg 2006;22:453-460.

7 Pinelli R, Ortiz D, Simonetto A, Bacchi C, Sala E, Alió JL: Correction of presbyopia in hyperopia with a center-distance, paracentral-near technique using the Technolas 217z platform. J Refract Surg 2008;24:494-500.

8 El Danasoury AM, Gamaly TO, Hantera M: Multizone LASIK with peripheral near zone for correction of presbyopia in myopic and hyperopic eyes: 1-year results. J Refract Surg 2009;25:296-305.

-9 Uthoff D, Pölzl M, Hepper D, Holland D: A new method of cornea modulation with excimer laser for simultaneous correction of presbyopia and ametropia. Graefes Arch Clin Exp Ophthalmol 2012;250:1649-1661. 
Black: Successful Restoration of Visual Acuity with an Extended Range of Vision Intraocular Lens after Multifocal Laser Ablation

10 Ryan A, O'Keefe M: Corneal approach to hyperopic presbyopia treatment: six-month outcomes of a new multifocal excimer laser in situ keratomileusis procedure. J Cataract Refract Surg 201;39:1226-1233.

11 Jackson WB, Tuan KM, Mintsioulis G: Aspheric wavefront-guided LASIK to treat hyperopic presbyopia: 12-month results with the VISX platform. J Refract Surg 2011;27:519-529.

12 TECNIS Symfony DFU, Z310939 Rev. 03 Revision Date: March 10, 2014.

$\checkmark 13$ Weeber HA, Piers PA: Theoretical performance of intraocular lenses correcting both spherical and chromatic aberration. J Refract Surg 2012;28:48-52.

14 Artal P, Manzanera S, Piers P, Weeber H: Visual effect of the combined correction of spherical and longitudinal chromatic aberrations. Opt Express 2010;18:1637-1648.

15 Cochener B: Discussion of clinical outcomes with an ERV IOL. Cataract Refract Surg Today Eur April 2016;35-37.
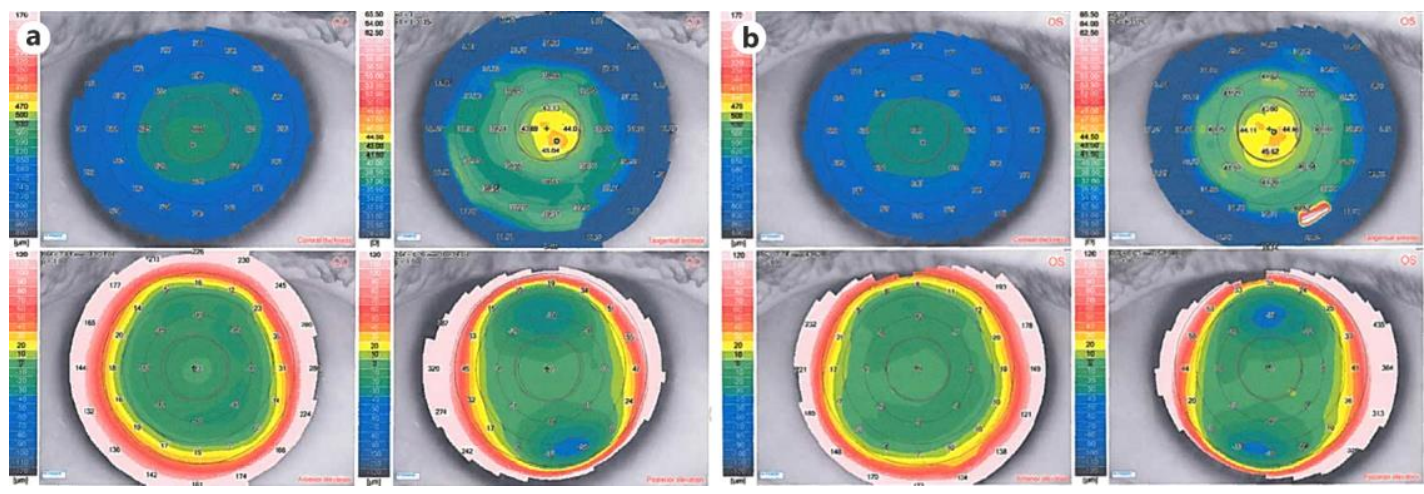

Fig. 1. Central steepening of the cornea after multifocal ablation in the right (a) and left (b) eye. 